\title{
The Role of T-Cell Subsets in Chronic Inflammation in Celiac Disease and Inflammatory Bowel Disease Patients: More Common Mechanisms or More Differences?
}

\author{
Tadakazu Hisamatsu $^{\text {a }}$ Ulrike Erben $^{\mathrm{b}, \mathrm{c}}$ Anja A. Kühl ${ }^{\mathrm{b}, \mathrm{c}}$ \\ aThe Third Department of Internal Medicine, Kyorin University School of Medicine, Mitaka, Tokyo, Japan; \\ ${ }^{\mathrm{b}}$ Medical Department (Gastroenterology/Infectious Diseases/Rheumatology) and ${ }^{\mathrm{C}}$ Research Center \\ ImmunoSciences, Campus Benjamin Franklin, Charité - Universitätsmedizin Berlin, Berlin, Germany
}

\section{Key Words}

Celiac disease · Crohn's disease - Cytokines - Microscopic colitis $\cdot \mathrm{T}$ cells $\cdot$ Ulcerative colitis

\begin{abstract}
Background: Chronic intestinal inflammation due to noninfectious causes represents a growing health issue all over the world. Celiac disease as well as inflammatory bowel diseases (IBD) like Crohn's disease and ulcerative and microscopic colitis involve uncontrolled T-cell activation and T-cell-mediated damage as common denominators. Therefore, diagnosis and treatment decisions clearly benefit from the knowledge of the intricacies of the systemic and the local T-cell activity. Summary: Depending on the cytokine milieu, CD4 ${ }^{+}$ $\mathrm{T}$ cells can differentiate into proinflammatory $\mathrm{T}$ helper 1 (Th1), anti-inflammatory Th2, antimicrobial Th17, pleiotropic Th9, tissue-instructing Th22 cells, and in the regulatory compartment forkhead box protein $3^{+}$Treg, suppressive Tr1 or Th3 cells. Additionally, follicular Th cells provide B-cell help in antibody class switching; cytotoxic $\mathrm{CD}^{+} \mathrm{T}$ cells target virus-infected or tumor cells. This review discusses our current knowledge on the contribution of defined T-cell subpopulations to establishing and maintaining chronic intestinal inflammation in either of the above entities. It also puts emphasis on the differences in the prevalence of these diseases
\end{abstract}

between Eastern and Western countries. Key Messages: In celiac disease, the driving role of T cells in the lamina propria and in the epithelium mainly specific for two defined antigens is well established. Differences in genetics and lifestyle between Western and Eastern countries were instrumental in understanding underlying mechanisms. In IBD, the vast amount of potential antigens and the corresponding antigen-specific $T$ cells makes it unlikely to find universal triggers. Increased mucosal $\mathrm{CD} 4^{+}$regulatory $\mathrm{T}$ cells in all four entities fail to control or abrogate local inflammatory processes. Thus, prevailing differences in the functional T-cell subtypes driving chronic intestinal inflammation in celiac disease and IBD at best allow some overlap in the treatment options for either disease.

(c) 2016 S. Karger AG, Basel

\section{Introduction}

Chronic intestinal inflammation clinically represents itself by frequent/recurrent vomiting, periods of (nonbloody) diarrhea and/or obstipation, abdominal pain, rectal bleeding, internal cramps and spasm, nausea, fever,

T. Hisamatsu and A.A. Kühl contributed equally to this work.

\section{KARGER}

E-Mail karger@karger.com

www.karger.com/iid
(C) 2016 S. Karger AG, Basel

2296-9403/16/0012-0052\$39.50/0
Anja A. Kühl

Medical Department (Gastroenterology/Infectious Diseases/Rheumatology)

Campus Benjamin Franklin, Charité - Universitätsmedizin Berlin

Hindenburgdamm 30, DE-12200 Berlin (Germany)

E-Mail anja.kuehl@charite.de 
Table 1. Prevalence of noninfectious chronic intestinal inflammation in different regions of the world

\begin{tabular}{llll}
\hline & USA & Europe & Asia \\
\hline Celiac disease & $710[1]$ & $1,000[2]$ & $<5[3]^{\mathrm{a}}$ \\
CD & $241[4]$ & $1.5-213[5]$ & $13.5[6]^{\mathrm{a}}$ \\
UC & $263[4]$ & $2.4-294[5]$ & $21.2[6]^{\mathrm{a}}$ \\
Microscopic colitis & & & \\
$\quad$ Lymphocytic & $39.3[7]$ & $\sim 39.3[8]$ & $\sim 39.3[8]$ \\
$\quad$ Collagenous & $63.7[7]$ & $\sim 63.7[8]$ & $\sim 63.7[8]$ \\
\hline
\end{tabular}

Numbers of patients suffering from the condition per 100,000 persons are given. Data from most recent available references. a Japan only.

weight loss and overall developmental delay in children. With infectious causes excluded, celiac disease and inflammatory bowel diseases (IBD) represented by Crohn's disease (CD), ulcerative colitis (UC) and microscopic colitis cover the main range of diagnoses for the self-driving immune disorders. Differences in the genetic backgrounds, lifestyles and diet of the populations define the uneven distribution of these conditions throughout the world (table 1).

Celiac disease peaks at two different ages, usually setting on in early childhood after weaning or in the 4th decade of life [9]. Although it affects more women than men, the latter show more severe manifestations [10]. With the advent of screening methods, celiac disease is diagnosed in an increasing number of individuals without overt clinical symptoms [11]. Celiac disease is very rare in Japan, where rice is the staple food [3]. In contrast, celiac disease is frequent (about 1 out of 100 people) in Western countries $[1,2]$.

As for the main entities of IBD, CD and UC can manifest at any age, but the peak of onset is 15-30 and 20-40 years of age, respectively, with both sexes equally affected [12]. The onset of microscopic colitis occurs at late ages (50-60 years). Overall, it is rare and affects more women than men [13]. While CD and UC are about 10 times more frequent in Western than in Eastern countries, the prevalence of microscopic colitis, though overall rare, is similar in developed countries $[7,8]$.

These epidemiologic background data corroborate chronic intestinal inflammation as a major health issue. They also highlight that detailed knowledge of cellular mechanisms driving the diseases helps to understand the relative contribution of external and intrinsic factors leading to the different types of chronic intestinal inflam- mation. T cells of various subtypes are deeply involved in initiating, maintaining and controlling chronic inflammation. We here thoroughly reviewed the literature searching for similarities and differences in celiac disease, $\mathrm{CD}, \mathrm{UC}$ and microscopic colitis with respect to the Tcell compartments. We also addressed the contribution of established regional epidemiologic differences to our knowledge on T cell-dependent mechanisms.

\section{Celiac Disease}

By its dependency on defined antigens, celiac disease represents a prototypic $\mathrm{CD} 4^{+} \mathrm{T}$ cell-dependent disease with chronic intestinal inflammation. A strict diet free of wheat and other cereals that contain gluten consisting of glutenin and gliadin ensures absence of intestinal symptoms [14]. Histopathologically, celiac disease is diagnosed by severe crypt hyperplasia and villous atrophy in the small intestine [15]. Specific antibodies, primarily autoantibodies directed at the tissue transglutaminase and antibodies directed at gliadin confirm the diagnosis $[15,16]$. In persons genetically predisposed by the human leukocyte antigen (HLA) class II variants DQ2 ( $\alpha 1^{*} 0501$, $\left.\beta 1^{*} 0201\right)$ and/or DQ8 $\left(\alpha 1^{*} 0301, \beta 1^{*} 0302\right), C D^{+} \mathrm{T}$ cells recognize gluten-derived peptides that are deaminated by the tissue transglutaminase and effectively presented by the said HLA-DQ variants $[17,18]$. Antigen-specific activated effector $\mathrm{CD} 4^{+} \mathrm{T}$ cells release proinflammatory cytokines, predominantly interferon- $\gamma($ IFN $\gamma)$ [19] and interleukin-21 (IL-21) (fig. 1) [20]. Albeit crucial to initiate the immunopathology in the small intestine, various other T-cell subsets are involved in sustaining the heterogeneous cytokine milieu maintaining or counteracting the local inflammation. Besides gluten-specific $\mathrm{CD} 4^{+} \mathrm{T}$ cells within the lamina propria, intraepithelial lymphocytes (IEL) are massively increased and considered a hallmark of celiac disease [21-23]. These IEL are $\mathrm{CD}^{+} \mathrm{T}$ cells carrying the $\alpha \beta \mathrm{T}$-cell receptor (TCR) or $\mathrm{CD} 4^{-} \mathrm{CD} 8^{-} \gamma \delta \mathrm{TCR}^{+}$ $\mathrm{T}$ cells [24]. Innate IEL are drastically reduced upon intestinal inflammation in celiac disease $[25,26]$. Both $\alpha \beta^{+}$ and $\gamma \delta^{+}$IEL express NKG2D [27], a receptor recognizing self-proteins induced by stress, infection and transformation [28], while the inhibitory NKG2A receptors are downregulated [29]. NKG2D is upregulated by IL-15 produced by epithelial cells and the myeloid-cell compartment within the lamina propria $[30,31]$. The oxidative stress in celiac disease $[32,33]$ leads to upregulation of the major histocompatibility complex class I chain-related protein A (MICA), the ligand for NKG2D, on epi- 
thelial cells [34]. Hence, upregulation of NKG2D on IEL and the upregulation of MICA on epithelial cells results in IEL-mediated cytolysis of epithelial cells [35]. For induction of villous atrophy, the IEL must acquire a fully activated NK phenotype [29]. In celiac disease, IEL express high levels of IL-15R $\alpha$ binding IL-15 with high affinity [36]. In these IEL, IL-15 enhances production of IFN $\gamma$ and tumor necrosis factor- $\alpha$ (TNFa) [30], induces proliferation [30] and has an antiapoptotic effect [37].

A small group of celiac disease patients do not respond to strict gluten-free diet and present with large numbers of aberrant IEL in a type 2 refractory celiac disease [38]. The abnormal cell phenotype includes the loss of surface CD3 with preservation of cytoplasmic CD3 $\varepsilon[39,40]$ and rearranged TCR $\gamma$ chains $[38,41]$. These abnormal and highly proliferative IEL are suggested to give rise to T-cell lymphoma [42], while others suggest innate IEL giving rise to enteropathy-associated T-cell lymphoma (EATL) $[26,43]$. However, lymphoma in celiac disease patients is not confined to the EATL [44].

Besides its effect on IEL, IL-15 acts on other immune cells within the mucosa. It enhances IL-21 production in lamina propria lymphocytes (LPL) [45] and renders effector $\mathrm{T}$ cells resistant to suppression by forkhead box P3 (Foxp3)-positive regulatory T cells (Treg) [46]. Foxp $3^{+}$is the master regulator of the development of Treg, which were first identified as $\mathrm{CD} 4{ }^{+} \mathrm{CD} 25^{\text {high }} \mathrm{T}$ cells [47]. In humans, Foxp3 gene mutation also causes multiorganic inflammatory disease known as immune dysregulation, polyendocrinopathy, enteropathy, X-linked syndrome $[48,49]$. Treg also express high levels of IL-15R $\alpha$ and are increased in the lamina propria of celiac disease patients, where they are mainly located beneath the epithelium [36, 50]. So far, the cytokine profile of these mucosal Treg was never examined. It is likely that they produce IL-10 and transforming growth factor- $\beta$ (TGF $\beta$ ) [51]. Early studies found normal IL-10 levels in the intestinal mucosa [32, 52]. Later, more sensitive approaches revealed increased levels of mucosal IL-10 mRNA [53]. As for the lymphocytes, IEL but not LPL are major sources of this IL-10 [54, 55]. Regarding mucosal TGF $\beta$ production in celiac disease patients, LPL seem to be the main producers $[56,57]$. Although mucosal TGF $\beta$ seems to be inefficient in counterbalancing the proinflammatory milieu with IL-15 being a strong opponent, TGF $\beta$ inhibits IL-2- but not IL15-dependent T-cell proliferation [58, 59]. Additionally, low concentrations of TGF $\beta$ in the presence of proinflammatory cytokines promote T helper 17 (Th17) differentiation [60]. Mucosal Th17 cells have been found in celiac disease [61-64], and elevated levels of IL-17A are associ-

\section{Celiac disease}

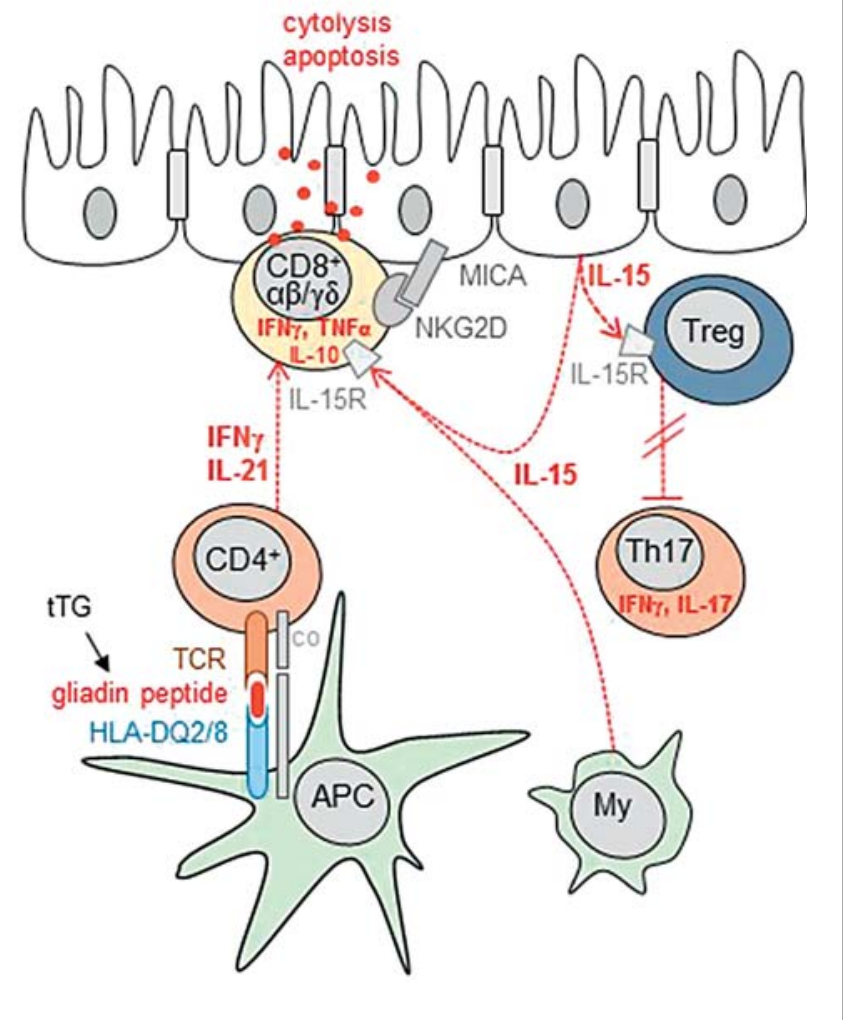

Fig. 1. Aspects of T-cell-dependent interactions and mediators within the ileal mucosa in celiac disease. APC = Antigen-presenting cell; co = co-stimulatory signal; $\mathrm{My}=$ monocytic cell; $\mathrm{tTG}=$ tissue transglutaminase.

ated with late-stage disease when villous atrophy has developed [65]. The main producers of IL- 17 are $\mathrm{CD} 4^{+}$and $\mathrm{CD} 4^{+} \mathrm{CD} 8^{+}$LPL [63]. The majority of these Th17 cells also produce IFN $\gamma$ [63]. Gliadin-specific Th17 cells display functional plasticity playing a dual role as effector memory cells expressing CD45RO, the CC chemokine receptor 6, the natural killer cell receptor NKR-P1A and the IL-23 receptor [62]. They also produce proinflammatory cytokines (IL-17, IFN $\gamma$ and IL-21) as well as the mucosaprotective cytokine IL-22 and regulatory TGF $\beta$ [62].

All T-cell subsets involved in celiac disease seem to be antigen-specific: gliadin-specific $\mathrm{CD} 4^{+} \mathrm{T}$ cells [18], gliadin-specific Th17 cells [62], tissue transglutaminase-specific T cells [66, 67], antigen-specific IEL [68]. Gliadin might be recognized by cytotoxic $\mathrm{CD} 8^{+} \mathrm{T}$ cells due to epitope spreading [69]. 


\section{Inflammatory Bowel Disease}

$\mathrm{CD}$ and UC are the two main forms of IBD. CD is a chronic inflammatory disease that could involve the entire digestive organ, especially the small bowel and the colon, leading to the progressive destruction of the alimentary tract. Inflammation in CD observed in the mucosal, submucosal and muscular layers causes intestinal complications such as fistulae, perforation and stricture. Chronic inflammation in UC mainly affects the colon and rectum. Endoscopic and radiological examination reveals continuous and diffuse mucosal inflammation from the rectum to the proximal colon. In UC, fistula formation is relatively rare compared to $\mathrm{CD}$, since the mucosal layer is a main target of inflammation. Another form of IBD, microscopic colitis, is mainly an inflammation of the large intestine, though the terminal ileum can be involved [70]. The term 'microscopic' refers to the fact that diagnosis demands microscopic examination. The patients suffer from chronic nonbloody diarrhea. On histology, lymphocytic and collagenous colitis appear as different entities $[71,72]$ that might be incorrectly grouped together [8]. In lymphocytic colitis, an increase in IEL to over 20 IEL counts per 100 enterocytes accompanies an architecturally normal colonic mucosa, a surface epithelial disarray and a mixed leukocytic infiltrate in the lamina propria [72-74]. Total IEL numbers are lower in collagenous colitis than in lymphocytic colitis [75]. Collagenous colitis shows an eponymous subepithelial collagen band of over $10 \mu \mathrm{m}$ without alterations in the overall local lymphocyte counts $[73,76,77]$.

In the local immunity of the intestinal mucosa, imbalances of T-cell subsets [e.g. Th1, Th2, Th17, Treg, natural killer T (NKT) cells] in the intestinal mucosa are hallmarks of IBD. The recent progress of research on the microbiota in mice has demonstrated that the intestinal flora can regulate $\mathrm{T}$-cell differentiation [78-82], suggesting that dysbiosis may play a role in IBD pathogenesis.

\section{Crohn's Disease}

Before the discovery of Th17, the classical concept of $\mathrm{CD}$ as a Th1-dominant disease was widely accepted. Numerous studies demonstrate that lamina propria $\mathrm{CD} 4^{+} \mathrm{T}$ cells isolated from CD patients produce high levels of IFN $\gamma$ (Th1). After the discovery of Th17 subsets, it has been reported that the IL-17-producing $\mathrm{T}$-cell population (Th17) is also increased in the lamina propria of CD patients as well as Th1 cells. At present, dysregulation of the

T Cells in Chronic Intestinal Inflammation innate immune system may trigger the onset of enhanced Th1- and Th17-acquired immune responses in CD. IL-12 and IL-23, mainly produced by dendritic cells and macrophages, play a key role in inducing the differentiation to Th1 cells. Indeed, mucosal IL-12 and IL-23 levels are elevated in CD patients $[83,84]$. Dendritic cells from the mesenteric lymph nodes in CD generated Th1 and Th17 cells in vitro [85]. Abnormally activated intestinal macrophages in CD patients producing abundant TNFa, IL-6, IL-23 and TNF-like ligand $1 \mathrm{~A}$ in response to commensal bacteria elicit an inflammation dominated by Th1 and Th17 cells [86-89]. The $\mathrm{CD} 14^{+}$macrophage subset is increased within the lamina propria of CD patients $[88,89]$. $\mathrm{CD} 14^{+}$macrophages also possess an antigen-presenting function inducing both Th1 and Th17 cells [86]. Interestingly, $\mathrm{CD} 14^{+}$macrophages can induce a T-cell population producing IFN $\gamma$ and IL-17 in vitro. Consistently, an IFN $\gamma^{+}$IL- $17^{+}$T-cell population was observed in the intestinal mucosa of CD patients [90]. As for the plasticity in the T-cell development, this double-positive T-cell population is thought to differ from Th17 cells [91]. Colitis models in mice suggested a central role of the IFN $\gamma^{+}$IL$17^{+} \mathrm{T}$ cells in chronic intestinal inflammation $[92,93]$. IL-21, mainly produced by activated $\mathrm{CD} 4^{+} \mathrm{T}$ cells and NKT cells, is required for Th17 cell differentiation, and the level of mucosal IL-21 is elevated in CD patients [94, 95].

IL-22 is a member of the IL-10 cytokine family that was recently discovered to be mainly produced by both adaptive and innate immune cells including dendritic cells, innate lymphoid cells, NK cells and $\mathrm{CD}^{+} \mathrm{T}$ cells. IL-22 regulates the intestinal immune status, especially enhancing barrier integrity and epithelial innate immunity. Among memory T cells, Th17 cells produce both IL-17 and IL-22. The novel T-cell subset Th22 produces IL-22, but neither IL-17 nor IFN $\gamma$. IL-22 produced by Th 22 cells and innate lymphoid cells may play a beneficial role in human CD $[96,97]$.

Despite accumulating evidence from experimental colitis that mucosal Treg contribute to intestinal immune homoeostasis and Treg dysfunction exacerbates colitis in mice, the role of Treg in human CD pathophysiology remains unclear. Treg in the human intestinal lamina propria were firstly identified as $\mathrm{CD} 4^{+} \mathrm{CD} 25^{\text {bright }}$ cells and were increased in the lamina propria of $\mathrm{CD}$ patients compared to normal controls [98]. The $\mathrm{CD} 4{ }^{+} \mathrm{CD} 25^{\text {bright }}$ Treg numbers were higher in inactive than in active $\mathrm{CD}$ [99]. Immunohistochemical evaluation of mucosal Foxp $3^{+}$ Treg corroborates the data from the periphery [99]. Treg accumulate in areas of active inflammation, including 


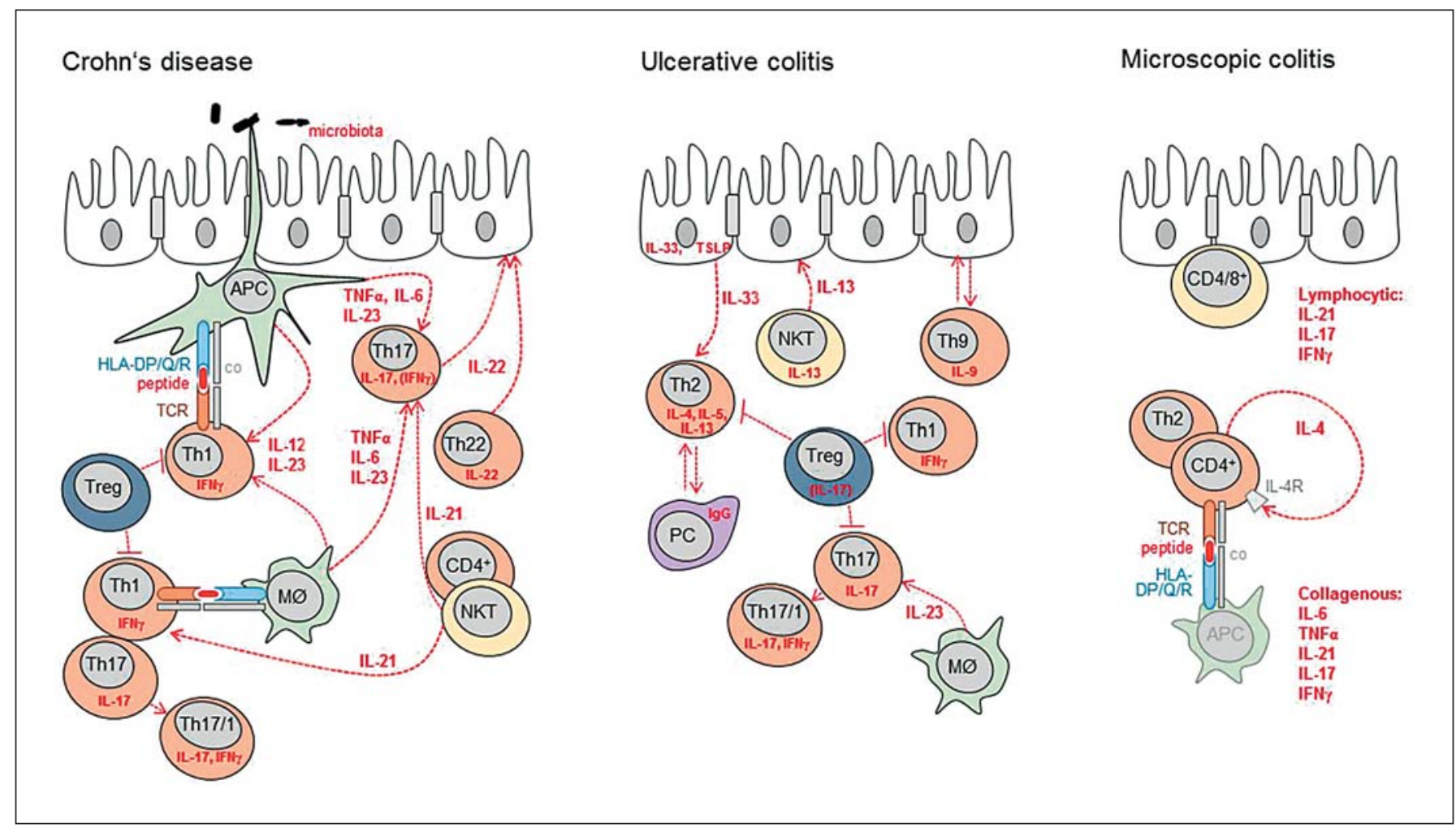

Fig. 2. Aspects of T-cell-dependent interactions within the intestinal mucosa in IBD. APC = Antigen-presenting cell; $\mathrm{co}=$ co-stimulatory signal; $\mathrm{M} \varnothing=\mathrm{CD} 14^{+}$macrophage; TSLP $=$thymic stromal lymphopoietin.

granulomas and retain potent regulatory activity ex vivo [100]. Linking these Treg to Th17 cells in CD, the Treg population includes IL-17-producing cells [101, 102].

\section{Ulcerative Colitis}

In human UC, several studies of the mucosal cytokine profile, especially containing IL-4, IL-5 and IL-13, supported the hypothesis of UC as a Th2-associated inflammation [103-110]. As a histopathological characteristic of UC, mucosal IgG1 ${ }^{+}$plasma cell infiltration is observed, suggesting Th2 polarization. In addition, several studies demonstrated enhanced expression of Th2-associated cytokine such as IL-33 and thymic stromal lymphopoietin in colonic epithelial cells of UC patients, also suggesting a preference for Th2 polarization [111-115]. Other reports do not show Th2 polarization in UC [116-119]. The missing efficacy of type 1 IFN in clinical trials for human UC also contradicts the hypothesis of the Th2 dominance [120]. Since Th1 and Th2 cytokines are found in the inflamed colon in UC $[105,110]$, the Th1/Th2 balance may vary depending on the severity and duration of the disease $[105,108]$. Recently, several reports suggested enhanced production of IL-13 by mucosal NKT cells [121, 122]. IL-13 produced by mucosal NKT cells is a key cytokine in the pathogenesis of oxazolone-induced colitis, a Th2-dominant colitis model representing human UC also insofar as high numbers of nonclassical NKT cells producing IL-13 are found in the colonic mucosa [122125]. IL-13 may play a role in the pathogenesis of UC by inducing epithelial cell damage [124, 126, 127]. Despite the accumulating evidence of IL-13 as a key molecule in a Th2-dominant mouse model of colitis as well as in human UC, anti-IL-13 therapy was not efficient in clinical trials with UC patients $[128,129]$. Additionally, in the actively inflamed mucosa of UC patients, IL- $22^{+}$cells were reduced [130]. In 2014, a novel helper T cell subset expressing the transcription factor PU.1 and IL-9 consequently named Th9 cells was identified in patients with UC [131]. IL-9 is closely associated with autoimmune diseases, regulates the function of the intestinal epithelial barrier and therefore plays a role in the pathogenesis of UC [132] (fig. 2). 
Recent studies have demonstrated that IL-17 also contributes to the pathogenesis of UC. IL-17 is expressed in the inflamed mucosa of UC patients $[83,106,133,134]$. Like in CD, IL-23 from CD $14^{+} \mathrm{CD} 68^{+}$macrophages promote Th17-cell immune responses crucially contributing to the chronic local inflammation of UC $[135,136]$. Additionally, the T-cell population double positive for IFN $\gamma$ and IL-17 and originating from Th17 cells is not specific for $\mathrm{CD}$ but also present in the intestinal mucosa of patients with active UC [90].

As for the regulatory T-cell compartment, increased Treg cells were also found in UC patients [98, 99, 137]. However, an IL- $17^{+}$Foxp $3^{+}$T-cell population in the peripheral blood of UC patients had impaired suppressive function ex vivo [138].

\section{Microscopic Colitis}

So far, little is known about the specifics of T-cell contribution to the course of microscopic colitis. It remains unclear whether local expansion or infiltration is responsible for an increase in T cells $[71,139]$. Absent correlation between the severity of the clinical symptoms and IEL numbers or thickness of the collagen layer as characteristic features of the two entities points to a dominance of the inflammatory infiltrates in the mucosal lamina propria [140]. The LPL composition strongly depends on the disease state and the exact origin of the samples [141], which might help to explain differences in the T-cell compartment found in independent surveys.

Immunohistochemistry clearly showed $\mathrm{CD}^{+}$IEL locally increased in the colon tissue [142-145]. Defining them as effector $\mathrm{T}$ cells, these $\mathrm{CD} 8^{+}$IEL predominantly express the transcription factor T-bet [144]. Flow cytometry indicates that $\mathrm{CD} 8^{+}$cells within the LPL might be in fact memory cells double positive for CD8 and CD4 [139, 143]. Immunohistochemistry also revealed LPL single positive for CD4 $[142,144,145]$. About $60 \%$ of the CD $4^{+}$ LPL were GATA- $3^{+}[144]$ pointing to Th2 cells activated by TCR dependent or independent of the IL-4 receptor [146]. Treg counts are more increased in collagenous than in lymphocytic colitis [147]. In patients initially diagnosed with lymphocytic colitis that later developed collagenous colitis, overall IEL numbers dropped while Treg counts increased [147].

Although not specific for $\mathrm{T}$ cells, additional but indirect evidence for the contribution of defined T-cell populations comes from studies on the local inflammatory environment as defined by cytokines and chemokines. IEL in microscopic colitis of both entities do not produce IL-15 [75]. Regarding mucosal cytokine production, mucosal mRNA of IFN- $\gamma$ and IL-12/35 p35 was upregulated, while protein levels were not statistically significantly different [139]. Increased protein levels of IL-6 and TNFa were found in the mucosa of collagenous colitis but not lymphocytic colitis patients, while IL-21 was increased in both entities [139]. Immunohistochemistry also revealed increased IL-17 and IFN $\gamma$ production [148]. Regarding Th2 cytokines, mucosal levels of IL-4, IL-5 and IL-10 were unaltered in microscopic colitis [139]. In the colonic mucosa of collagenous colitis patients, IFN $\gamma$, TNF, IL-17, IL- $1 \beta$ and IL- 6 but not IL- 4 or IL- 10 were found enhanced [149]. Chemokines and their receptors especially associated with $\mathrm{CD}^{+} \mathrm{T}$ cells in colon biopsies and overall low $\mathrm{CD} 4^{+} \mathrm{T}$-cell counts, except for Treg, provide additional indirect evidence for a central role of $\mathrm{CD}^{+} \mathrm{T}$ cells in both entities [71].

Taken together, a closer look at the subgroups within the intestinal T-cell compartments in microscopic colitis might shed light on the sequence of inflammatory processes in individual patients and might clarify whether the types of microscopic colitis indeed are independent entities or if and under which conditions lymphocytic colitis also precedes the collagenous type.

\section{Common and Different T-Cell-Dependent Mechanisms in Celiac Disease and IBD}

The cytokines IL-17, IL-21 and IFN $\gamma$ are increased in celiac disease and IBD, while an increase in IL-15 is only attributed to celiac disease. In celiac disease, antigen-specific $\mathrm{CD} 4^{+} \mathrm{LPL}$ and IEL $\left(\mathrm{CD} 8^{+}\right.$and $\left.\mathrm{CD} 4^{-} \mathrm{CD} 8^{-} \gamma \delta \mathrm{TCR}^{+}\right)$ are the main drivers of the disease. Antigen-specific $\mathrm{T}$ cells might be critically involved in IBD too. Our lack of knowledge of defined antigens and the vast amount of potential candidates against the background of a variety of genetic dispositions renders it difficult to name common antigen-specific T-cell populations. The underlying assumption that individual combinations of antigens and presenting cells might be critical directs our hopes to the accessibility of high-throughput techniques. Although playing a role in microscopic colitis, IEL show no increased production of IL-15. Mucosal Treg are increased in celiac disease as well as in IBD. A specific Treg cell population also producing IL-17 in the mucosa of CD shows no impairment in regulatory capacity, while the suppressive activity of these cells was diminished in UC patients. As for microscopic colitis, Treg are more increased in lymphocytic than collagenous colitis. 
In the past, $\mathrm{CD}$ was accepted as a Th1-dominated disease, while UC to be mainly mediated by Th2 cells. With the discovery of Th17 cells, it is acknowledged, that these cells contribute to the recurrent chronic intestinal inflammation in CD and that in UC Th1 cytokines are also increased. In microscopic colitis, Th1 cytokines are increased, while Th2 cytokines are unaltered. Also marking a difference in the IBD entities, Th22 cells are increased in CD but decreased in UC. Nothing is known so far about Th22 cells in celiac disease or microscopic colitis. The producers of IL-22 in the mucosa of celiac disease patients are Th17 cells. The hypothesis of altered Th1/Th2 or Th1/ Th17 balance in the IBD pathogenesis seems very attractive. However, the mucosal immune status is more complex in IBD in humans than in inbred mouse models. Except for anti-TNFa and IL-12p40, targeting specific proinflammatory cytokines involved in the balance of local T-cell subsets in IBD treatment does not present promising additional therapeutic strategies yet. Clinical trials of both anti-IFN $\gamma \mathrm{mAb}$ (Th1) and anti-IL-17A mAb (Th17) in CD did not show significant efficacy $[150,151]$.

The role of Th17 in the pathogenesis of UC is also suggested in translational researches in patients treated with the anti-TNF $\alpha \mathrm{mAb}$ infliximab. A subanalysis of the Ac- tive Colitis Trial 1 revealed that the expression profiles of Th1-, Th2- and Th17-related cytokines in mucosal biopsy specimens were altered in the group of UC patients responding to the treatment with clinical remission [152]. The $\mathrm{CD} 8^{+}$macrophage-Th17 cell axis could be a therapeutic target for infliximab in UC as well as in CD [153, 154]. Infliximab has also been shown to be beneficial for patients with severe refractory celiac disease $[155,156]$. For the treatment of diet nonresponsive celiac disease and refractory celiac disease, an IL-15 antibody is launched for testing in phase II by Celimmune. Microscopic colitis patients will require corticosteroid or immunosuppressive treatments, or even surgical intervention in refractory cases [157].

In conclusion, comparing $\mathrm{T}$ cell-dependent mechanisms in intestinal inflammation revealed more differences than similarities in the entities UC, CD, microscopic colitis and celiac disease.

\section{Disclosure Statement}

None of the authors has any potential financial conflict of interest related to this study.

\section{References}

-1 Rubio-Tapia A, Ludvigsson JF, Brantner TL, et al: The prevalence of celiac disease in the United States. Am J Gastroenterol 2012;107: 1538-1544; quiz 1537, 1545.

$\checkmark 2$ Mustalahti K, Catassi C, Reunanen A, et al: The prevalence of celiac disease in Europe: results of a centralized, international mass screening project. Ann Med 2010;42:587-595.

3 Cummins AG, Roberts-Thomson IC: Prevalence of celiac disease in the Asia-Pacific region. J Gastroenterol Hepatol 2009;24:13471351.

4 Kappelman MD, Moore KR, Allen JK, et al: Recent trends in the prevalence of Crohn's disease and ulcerative colitis in a commercially insured US population. Dig Dis Sci 2013;58: 519-525.

5 Burisch J, Jess T, Martinato M, et al: The burden of inflammatory bowel disease in Europe. J Crohns Colitis 2013;7:322-337.

6 Prideaux L, Kamm MA, De Cruz PP, et al: Inflammatory bowel disease in Asia: a systematic review. J Gastroenterol Hepatol 2012;27: 1266-1280.

7 Sonnenberg A, Genta RM: Geographic distributions of microscopic colitis and inflammatory bowel disease in the United States. Inflamm Bowel Dis 2012;18:2288-2293.
-8 Storr MA: Microscopic colitis: epidemiology, pathophysiology, diagnosis and current management-an update 2013. ISRN Gastroenterol 2013;2013:352718.

-9 Catassi C, Kryszak D, Bhatti B, et al: Natural history of celiac disease autoimmunity in a USA cohort followed since 1974. Ann Med 2010;42:530-538.

10 Bai D, Brar P, Holleran S, et al: Effect of gender on the manifestations of celiac disease: evidence for greater malabsorption in men. Scand J Gastroenterol 2005;40:183-187.

11 Barker JM, Liu E: Celiac disease: pathophysiology, clinical manifestations, and associated autoimmune conditions. Adv Pediatr 2008; 55:349-365.

12 Birrenbach T, Bocker U: Inflammatory bowel disease and smoking: a review of epidemiology, pathophysiology, and therapeutic implications. Inflamm Bowel Dis 2004;10:848-859.

13 Yen EF, Pokhrel B, Du H, et al: Current and past cigarette smoking significantly increase risk for microscopic colitis. Inflamm Bowel Dis $2012 ; 18: 1835-1841$.

14 Wieser H: Chemistry of gluten proteins. Food Microbiol 2007;24:115-119.

15 Trier JS: Celiac sprue. N Engl J Med 1991;325: 1709-1719.
16 Dieterich W, Laag E, Schopper H, et al: Autoantibodies to tissue transglutaminase as predictors of celiac disease. Gastroenterology 1998;115:1317-1321.

17 Anderson RP, Degano P, Godkin AJ, et al: In vivo antigen challenge in celiac disease identifies a single transglutaminase-modified peptide as the dominant A-gliadin T-cell epitope. Nat Med 2000;6:337-342.

18 Lundin KE, Scott H, Fausa O, et al: T cells from the small intestinal mucosa of a DR4, DQ7/DR4, DQ8 celiac disease patient preferentially recognize gliadin when presented by DQ8. Hum Immunol 1994;41:285-291.

19 Nilsen EM, Lundin KE, Krajci P, et al: Gluten specific, HLA-DQ restricted T cells from coeliac mucosa produce cytokines with Th1 or Th0 profile dominated by interferon gamma. Gut 1995;37:766-776.

20 Bodd M, Raki M, Tollefsen S, et al: HLADQ2-restricted gluten-reactive $\mathrm{T}$ cells produce IL-21 but not IL-17 or IL-22. Mucosal Immunol 2010;3:594-601.

21 Chang F, Mahadeva U, Deere H: Pathological and clinical significance of increased intraepithelial lymphocytes (IELs) in small bowel mucosa. APMIS 2005;113:385-399. 
22 Marsh MN: Gluten, major histocompatibility complex, and the small intestine. A molecular and immunobiologic approach to the spectrum of gluten sensitivity ('celiac sprue'). Gastroenterology 1992;102:330-354.

-23 Oberhuber G, Granditsch G, Vogelsang H: The histopathology of coeliac disease: time for a standardized report scheme for pathologists. Eur J Gastroenterol Hepatol 1999;11: 1185-1194.

24 Sollid LM: Intraepithelial lymphocytes in celiac disease: license to kill revealed. Immunity 2004;21:303-304.

25 Eiras P, Roldan E, Camarero C, et al: Flow cytometry description of a novel CD3-/CD7+ intraepithelial lymphocyte subset in human duodenal biopsies: potential diagnostic value in coeliac disease. Cytometry 1998;34:95-102.

-26 Schmitz F, Kooy-Winkelaar Y, Wiekmeijer AS, et al: The composition and differentiation potential of the duodenal intraepithelial innate lymphocyte compartment is altered in coeliac disease. Gut 2015, Epub ahead of print.

27 Bauer S, Groh V, Wu J, et al: Activation of NK cells and $\mathrm{T}$ cells by NKG2D, a receptor for stress-inducible MICA. Science 1999;285: 727-729.

$\checkmark 28$ Medzhitov R, Janeway CA Jr: Decoding the patterns of self and nonself by the innate immune system. Science 2002;296:298-300.

29 Setty M, Discepolo V, Abadie V, et al: Distinct and synergistic contributions of epithelial stress and adaptive immunity to functions of intraepithelial killer cells and active celiac disease. Gastroenterology 2015;149:681-691 e10.

-30 Di Sabatino A, Ciccocioppo R, Cupelli F, et al: Epithelium derived interleukin 15 regulates intraepithelial lymphocyte Th1 cytokine production, cytotoxicity, and survival in coeliac disease. Gut 2006;55:469-477.

- 31 Meresse B, Malamut G, Cerf-Bensussan N: Celiac disease: an immunological jigsaw. Immunity 2012;36:907-919.

32 Beckett CG, Dell'Olio D, Shidrawi RG, et al: Gluten-induced nitric oxide and pro-inflammatory cytokine release by cultured coeliac small intestinal biopsies. Eur J Gastroenterol Hepatol 1999;11:529-535.

-33 Murray IA, Daniels I, Coupland K, et al: Increased activity and expression of iNOS in human duodenal enterocytes from patients with celiac disease. Am J Physiol Gastrointest Liver Physiol 2002;283:G319-G326.

34 Martin-Pagola A, Perez-Nanclares G, Ortiz L, et al: MICA response to gliadin in intestinal mucosa from celiac patients. Immunogenetics 2004;56:549-554.

35 Meresse B, Chen Z, Ciszewski C, et al: Coordinated induction by IL15 of a TCR-independent NKG2D signaling pathway converts CTL into lymphokine-activated killer cells in celiac disease. Immunity 2004;21:357-366.
Zanzi D, Stefanile R, Santagata S, et al: IL-15 interferes with suppressive activity of intestinal regulatory $\mathrm{T}$ cells expanded in Celiac disease. Am J Gastroenterol 2011;106:1308-1317.

- 37 Malamut G, El Machhour R, Montcuquet N, et al: IL-15 triggers an antiapoptotic pathway in human intraepithelial lymphocytes that is a potential new target in celiac disease-associated inflammation and lymphomagenesis. J Clin Invest 2010;120:2131-2143.

38 Cellier C, Delabesse E, Helmer C, et al: Refractory sprue, coeliac disease, and enteropathyassociated T-cell lymphoma. French Coeliac Disease Study Group. Lancet 2000;356:203208.

39 Patey-Mariaud De Serre N, Cellier C, Jabri B, et al: Distinction between coeliac disease and refractory sprue: a simple immunohistochemical method. Histopathology 2000;37: 70-77.

40 Rubio-Tapia A, Murray JA: Classification and management of refractory coeliac disease. Gut 2010;59:547-557.

41 Daum S, Weiss D, Hummel M, et al: Frequency of clonal intraepithelial T lymphocyte proliferations in enteropathy-type intestinal $\mathrm{T}$ cell lymphoma, coeliac disease, and refractory sprue. Gut 2001;49:804-812.

42 Brousse N, Meijer JW: Malignant complications of coeliac disease. Best Pract Res Clin Gastroenterol 2005;19:401-412.

43 Gunther U, Holloway JA, Gordon JN, et al: Phenotypic characterization of CD3-7+ cells in developing human intestine and an analysis of their ability to differentiate into $\mathrm{T}$ cells. J Immunol 2005;174:5414-5422.

44 Smedby KE, Akerman M, Hildebrand H, et al: Malignant lymphomas in coeliac disease: evidence of increased risks for lymphoma types other than enteropathy-type T cell lymphoma. Gut 2005;54:54-59.

45 Sarra M, Cupi ML, Monteleone I, et al: IL-15 positively regulates IL-21 production in celiac disease mucosa. Mucosal Immunol 2013;6: 244-255.

46 Hmida NB, Ben Ahmed M, Moussa A, et al: Impaired control of effector $\mathrm{T}$ cells by regulatory T cells: a clue to loss of oral tolerance and autoimmunity in celiac disease? Am J Gastroenterol 2012;107:604-611.

47 Sakaguchi S, Sakaguchi N, Asano M, et al: Immunologic self-tolerance maintained by activated T cells expressing IL-2 receptor alpha-chains (CD25). Breakdown of a single mechanism of self-tolerance causes various autoimmune diseases. J Immunol 1995;155: 1151-1164.

48 Bennett CL, Christie J, Ramsdell F, et al: The immune dysregulation, polyendocrinopathy, enteropathy, X-linked syndrome (IPEX) is caused by mutations of FOXP3. Nat Genet 2001;27:20-21.

49 Wildin RS, Ramsdell F, Peake J, et al: X-linked neonatal diabetes mellitus, enteropathy and endocrinopathy syndrome is the human equivalent of mouse scurfy. Nat Genet 2001; 27:18-20.
50 Cianci R, Cammarota G, Frisullo G, et al: Tissue-infiltrating lymphocytes analysis reveals large modifications of the duodenal 'immunological niche' in coeliac disease after gluten-free diet. Clin Transl Gastroenterol 2012; 3:e28.

51 Gianfrani C, Levings MK, Sartirana C, et al: Gliadin-specific type 1 regulatory $\mathrm{T}$ cells from the intestinal mucosa of treated celiac patients inhibit pathogenic T cells. J Immunol 2006; 177:4178-4186.

52 Lahat N, Shapiro S, Karban A, et al: Cytokine profile in coeliac disease. Scand J Immunol 1999;49:441-446.

53 Salvati VM, Mazzarella G, Gianfrani C, et al: Recombinant human interleukin 10 suppresses gliadin dependent $\mathrm{T}$ cell activation in ex vivo cultured coeliac intestinal mucosa. Gut 2005;54:46-53.

-54 Forsberg G, Hernell O, Hammarstrom S, et al: Concomitant increase of IL-10 and pro-inflammatory cytokines in intraepithelial lymphocyte subsets in celiac disease. Int Immunol 2007;19:993-1001.

55 Forsberg G, Hernell O, Melgar S, et al: Paradoxical coexpression of proinflammatory and down-regulatory cytokines in intestinal $\mathrm{T}$ cells in childhood celiac disease. Gastroenterology 2002;123:667-678.

56 Hansson T, Ulfgren AK, Lindroos E, et al: Transforming growth factor-beta (TGF-beta) and tissue transglutaminase expression in the small intestine in children with coeliac disease. Scand J Immunol 2002;56:530-537.

57 Lionetti P, Pazzaglia A, Moriondo M, et al: Differing patterns of transforming growth factor-beta expression in normal intestinal mucosa and in active celiac disease. J Pediatr Gastroenterol Nutr 1999;29:308-313.

58 Benahmed M, Meresse B, Arnulf B, et al: Inhibition of TGF-beta signaling by IL-15: a new role for IL-15 in the loss of immune homeostasis in celiac disease. Gastroenterology 2007;132:994-1008.

59 Kehrl JH, Wakefield LM, Roberts AB, et al Production of transforming growth factor beta by human $\mathrm{T}$ lymphocytes and its potential role in the regulation of $\mathrm{T}$ cell growth. J Exp Med 1986;163:1037-1050.

-60 O'Garra A, Stockinger B, Veldhoen M: Differentiation of human $\mathrm{T}(\mathrm{H})-17$ cells does require TGF-beta! Nat Immunol 2008;9:588590

61 Castellanos-Rubio A, Santin I, Irastorza I, et al: TH17 (and TH1) signatures of intestinal biopsies of $\mathrm{CD}$ patients in response to gliadin. Autoimmunity 2009;42:69-73.

62 Fernandez S, Molina IJ, Romero P, et al: Characterization of gliadin-specific Th17 cells from the mucosa of celiac disease patients. Am J Gastroenterol 2011;106:528-538.

63 Monteleone I, Sarra M, Del Vecchio Blanco G, et al: Characterization of IL-17A-producing cells in celiac disease mucosa. J Immunol 2010;184:2211-2218.
T Cells in Chronic Intestinal Inflammation
Inflamm Intest Dis 2016;1:52-62 
64 Sjoberg V, Sandstrom O, Hedberg M, et al: Intestinal T-cell responses in celiac disease impact of celiac disease associated bacteria. PLoS One 2013;8:e53414.

65 Lahdenpera AI, Falth-Magnusson K, Hogberg L, et al: Expression pattern of T-helper 17 cell signaling pathway and mucosal inflammation in celiac disease. Scand J Gastroenterol 2014;49:145-156.

-66 Ciccocioppo R, Finamore A, Mengheri E, et al: Isolation and characterization of circulating tissue transglutaminase-specific $\mathrm{T}$ cells in coeliac disease. Int J Immunopathol Pharmacol 2010;23:179-191.

67 Comerford R, Coates C, Byrne G, et al: Characterisation of tissue transglutaminase-reactive $\mathrm{T}$ cells from patients with coeliac disease and healthy controls. Clin Immunol 2014; 154:155-163.

68 Han A, Newell EW, Glanville J, et al: Dietary gluten triggers concomitant activation of CD4+ and CD8+ alphabeta T cells and gammadelta $\mathrm{T}$ cells in celiac disease. Proc Natl Acad Sci USA 2013;110:13073-13078.

69 Gianfrani C, Camarca A, Mazzarella G, et al: Extensive in vitro gastrointestinal digestion markedly reduces the immune-toxicity of Triticum monococcum wheat: implication for celiac disease. Mol Nutr Food Res 2015;59: 1844-1854.

70 Sapp H, Ithamukkala S, Brien TP, et al: The terminal ileum is affected in patients with lymphocytic or collagenous colitis. Am J Surg Pathol 2002;26:1484-1492.

71 Gunaltay S, Kumawat AK, Nyhlin N, et al: Enhanced levels of chemokines and their receptors in the colon of microscopic colitis patients indicate mixed immune cell recruitment. Mediators Inflamm 2015;2015:132458.

72 Tysk C, Bohr J, Nyhlin N, et al: Diagnosis and management of microscopic colitis. World J Gastroenterol 2008;14:7280-7288.

73 Carmack SW, Lash RH, Gulizia JM, et al: Lymphocytic disorders of the gastrointestinal tract: a review for the practicing pathologist. Adv Anat Pathol 2009;16:290-306.

74 Liszka L, Woszczyk D, Pajak J: Histopathological diagnosis of microscopic colitis. J Gastroenterol Hepatol 2006;21:792-797.

75 Tagkalidis PP, Gibson PR, Bhathal PS: Microscopic colitis demonstrates a Thelper cell type 1 mucosal cytokine profile. J Clin Pathol 2007; 60:382-387.

76 Magro F, Langner C, Driessen A, et al: European consensus on the histopathology of inflammatory bowel disease. J Crohns Colitis 2013;7:827-851.

77 Salas A, Fernandez-Banares F, Casalots J, et al: Subepithelial myofibroblasts and tenascin expression in microscopic colitis. Histopathology 2003;43:48-54.

78 Atarashi K, Nishimura J, Shima T, et al: ATP drives lamina propria $\mathrm{T}(\mathrm{H}) 17$ cell differentiation. Nature 2008;455:808-812.

-79 Atarashi K, Tanoue T, Ando M, et al: Th17 cell induction by adhesion of microbes to intestinal epithelial cells. Cell 2015;163:367-380.
80 Atarashi K, Tanoue T, Shima T, et al: Induction of colonic regulatory $\mathrm{T}$ cells by indigenous Clostridium species. Science 2011;331: 337-341.

81 Ivanov II, Atarashi K, Manel N, et al: Induction of intestinal Th17 cells by segmented filamentous bacteria. Cell 2009;139:485-498.

82 Mazmanian SK, Round JL, Kasper DL: A microbial symbiosis factor prevents intestinal inflammatory disease. Nature 2008;453:620625.

83 Fujino S, Andoh A, Bamba S, et al: Increased expression of interleukin 17 in inflammatory bowel disease. Gut 2003;52:65-70.

84 Matsuoka K, Inoue N, Sato T, et al: T-bet upregulation and subsequent interleukin 12 stimulation are essential for induction of Th1 mediated immunopathology in Crohn's disease. Gut 2004;53:1303-1308.

85 Sakuraba A, Sato T, Kamada N, et al: Th1/Th17 immune response is induced by mesenteric lymph node dendritic cells in Crohn's disease. Gastroenterology 2009;137:1736-1745.

86 Kamada N, Hisamatsu T, Honda H, et al: Human CD14+ macrophages in intestinal lamina propria exhibit potent antigen-presenting ability. J Immunol 2009;183:1724-1731.

87 Kamada N, Hisamatsu T, Honda H, et al: TL1A produced by lamina propria macrophages induces Th1 and Th17 immune responses in cooperation with IL-23 in patients with Crohn's disease. Inflamm Bowel Dis 2010;16:568-575.

88 Kamada N, Hisamatsu T, Okamoto S, et al: Unique CD14 intestinal macrophages contribute to the pathogenesis of Crohn disease via IL-23/IFN-gamma axis. J Clin Invest 2008; 118:2269-2280

89 Ogino T, Nishimura J, Barman S, et al: Increased Th17-inducing activity of CD14+ CD163 low myeloid cells in intestinal lamina propria of patients with Crohn's disease. Gastroenterology 2013;145:1380-1391 e1.

90 Globig AM, Hennecke N, Martin B, et al: Comprehensive intestinal $\mathrm{T}$ helper cell profiling reveals specific accumulation of IFNgamma+IL-17+coproducing CD4+ T cells in active inflammatory bowel disease. Inflamm Bowel Dis 2014;20:2321-1329.

91 Lee YK, Turner H, Maynard CL, et al: Late developmental plasticity in the T helper 17 lineage. Immunity 2009;30:92-107.

92 Harbour SN, Maynard CL, Zindl CL, et al: Th17 cells give rise to Th1 cells that are required for the pathogenesis of colitis. Proc Natl Acad Sci USA 2015;112:7061-7066.

93 Sujino T, Kanai T, Ono Y, et al: Regulatory T cells suppress development of colitis, blocking differentiation of T-helper 17 into alternative T-helper 1 cells. Gastroenterology 2011; 141:1014-1023.

94 Fantini MC, Monteleone G, MacDonald TT: IL-21 comes of age as a regulator of effector T cells in the gut. Mucosal Immunol 2008; 1 : $110-115$.
-95 Monteleone G, Monteleone I, Fina D, et al Interleukin-21 enhances T-helper cell type I signaling and interferon-gamma production in Crohn's disease. Gastroenterology 2005; 128:687-694.

96 Geremia A, Arancibia-Carcamo CV, Fleming MP, et al: IL-23-responsive innate lymphoid cells are increased in inflammatory bowel disease. J Exp Med 2011;208:11271133.

97 Wolk K, Witte E, Hoffmann U, et al: IL-22 induces lipopolysaccharide-binding protein in hepatocytes: a potential systemic role of IL-22 in Crohn's disease. J Immunol 2007; 178:5973-5981.

$\$ 98$ Makita S, Kanai T, Oshima S, et al CD4+CD25bright $\mathrm{T}$ cells in human intestinal lamina propria as regulatory cells. J Immunol 2004;173:3119-3130.

$\$ 99$ Maul J, Loddenkemper C, Mundt P, et al: Peripheral and intestinal regulatory $\mathrm{CD} 4+$ CD25(high) $\mathrm{T}$ cells in inflammatory bowel disease. Gastroenterology 2005;128:18681878.

100 Saruta M, Yu QT, Fleshner PR, et al: Characterization of FOXP3+CD4+ regulatory T cells in Crohn's disease. Clin Immunol 2007; 125:281-290.

101 Hovhannisyan Z, Treatman J, Littman DR, et al: Characterization of interleukin-17producing regulatory $\mathrm{T}$ cells in inflamed intestinal mucosa from patients with inflammatory bowel diseases. Gastroenterology 2011;140:957-965.

102 Lord JD, Valliant-Saunders K, Hahn H, et al: Paradoxically increased FOXP3+ T cells in IBD do not preferentially express the isoform of FOXP3 lacking exon 2. Dig Dis Sci 2012;57:2846-2855.

103 Berrebi D, Languepin J, Ferkdadji L, et al: Cytokines, chemokine receptors, and homing molecule distribution in the rectum and stomach of pediatric patients with ulcerative colitis. J Pediatr Gastroenterol Nutr 2003;37: 300-308.

104 Giacomelli R, Passacantando A, Parzanese I, et al: Serum levels of soluble CD30 are increased in ulcerative colitis (UC) but not in Crohn's disease (CD). Clin Exp Immunol 1998;111:532-535.

105 Hart AL, Kamm MA, Knight SC, et al: Prospective evaluation of intestinal homing memory $\mathrm{T}$ cells in ulcerative colitis. Inflamm Bowel Dis 2004;10:496-503.

106 Iboshi Y, Nakamura K, Ihara E, et al: Multigene analysis unveils distinctive expression profiles of helper T-cell-related genes in the intestinal mucosa that discriminate between ulcerative colitis and Crohn's disease. Inflamm Bowel Dis 2014;20:967-977.

107 Inoue S, Matsumoto T, Iida M, et al: Characterization of cytokine expression in the rectal mucosa of ulcerative colitis: correlation with disease activity. Am J Gastroenterol 1999;94:2441-2446. 
108 Matsuzaki K, Hokari R, Kato S, et al: Differential expression of CCR5 and CRTH2 on infiltrated cells in colonic mucosa of patients with ulcerative colitis. J Gastroenterol Hepatol 2003; 18:1081-1088.

109 Mullin GE, Maycon ZR, Braun-Elwert L, et al: Inflammatory bowel disease mucosal biopsies have specialized lymphokine mRNA profiles. Inflamm Bowel Dis 1996;2:16-26.

110 Ohtani K, Ohtsuka Y, Ikuse T, et al: Increased mucosal expression of GATA-3 and STAT-4 in pediatric ulcerative colitis. Pediatr Int 2010;52:584-589.

-111 Beltran CJ, Nunez LE, Diaz-Jimenez D, et al: Characterization of the novel ST2/IL-33 system in patients with inflammatory bowel disease. Inflamm Bowel Dis 2010;16:10971107.

112 Pastorelli L, Garg RR, Hoang SB, et al: Epithelial-derived IL-33 and its receptor ST2 are dysregulated in ulcerative colitis and in experimental Th1/Th2 driven enteritis. Proc Natl Acad Sci USA 2010;107:8017-8022.

-113 Seidelin JB, Bjerrum JT, Coskun M, et al: IL33 is upregulated in colonocytes of ulcerative colitis. Immunol Lett 2010;128:80-85.

114 Seidelin JB, Coskun M, Kvist PH, et al: IL-33 promotes GATA-3 polarization of gut-derived $\mathrm{T}$ cells in experimental and ulcerative colitis. J Gastroenterol 2015;50:180-190.

-115 Tanaka J, Saga K, Kido M, et al: Proinflammatory Th2 cytokines induce production of thymic stromal lymphopoietin in human colonic epithelial cells. Dig Dis Sci 2010;55: 1896-1904.

116 Camoglio L, Te Velde AA, Tigges AJ, et al: Altered expression of interferon-gamma and interleukin-4 in inflammatory bowel disease. Inflamm Bowel Dis 1998;4:285-290.

117 Funakoshi K, Sugimura K, Sasakawa T, et al: Study of cytokines in ulcerative colitis. J Gastroenterol 1995;30(suppl 8):61-63.

118 Niessner M, Volk BA: Altered Th1/Th2 cytokine profiles in the intestinal mucosa of patients with inflammatory bowel disease as assessed by quantitative reversed transcribed polymerase chain reaction (RT-PCR). Clin Exp Immunol 1995;101:428-435.

119 Radford-Smith G, Jewell DP: Cytokines and inflammatory bowel disease. Baillieres Clin Gastroenterol 1996;10:151-164.

120 Seow CH, Benchimol EI, Griffiths AM, et al: Type I interferons for induction of remission in ulcerative colitis. Cochrane Database Syst Rev 2008;CD006790.

-121 Camelo A, Barlow JL, Drynan LF, et al: Blocking IL-25 signalling protects against gut inflammation in a type- 2 model of colitis by suppressing nuocyte and NKT derived IL-13. J Gastroenterol 2012;47:1198-1211.

122 Fuss IJ, Heller F, Boirivant M, et al: Nonclassical CD1d-restricted NK T cells that produce IL-13 characterize an atypical Th2 response in ulcerative colitis. J Clin Invest 2004;113:1490-1497.
123 Boirivant M, Fuss IJ, Chu A, et al: Oxazolone colitis: a murine model of $\mathrm{T}$ helper cell type 2 colitis treatable with antibodies to interleukin 4. J Exp Med 1998;188:1929-1939.

124 Heller F, Florian P, Bojarski C, et al: Interleukin-13 is the key effector Th2 cytokine in ulcerative colitis that affects epithelial tight junctions, apoptosis, and cell restitution. Gastroenterology 2005;129:550-564.

125 Heller F, Fuss IJ, Nieuwenhuis EE, et al: Oxazolone colitis, a Th2 colitis model resembling ulcerative colitis, is mediated by IL13-producing NK-T cells. Immunity 2002; 17:629-638.

126 Kawashima R, Kawamura YI, Kato R, et al: IL-13 receptor alpha2 promotes epithelial cell regeneration from radiation-induced small intestinal injury in mice. Gastroenterology 2006;131:130-141.

127 Kawashima R, Kawamura YI, Oshio T, et al: Interleukin-13 damages intestinal mucosa via TWEAK and Fn14 in mice-a pathway associated with ulcerative colitis. Gastroenterology 2011;141:2119-2129 e8.

128 Danese S, Rudzinski J, Brandt W, et al: Tralokinumab for moderate-to-severe UC: a randomised, double-blind, placebo-controlled, phase IIa study. Gut 2015;64:243249.

129 Reinisch W, Panes J, Khurana S, et al: Anrukinzumab, an anti-interleukin 13 monoclonal antibody, in active UC: efficacy and safety from a phase IIa randomised multicentre study. Gut 2015;64:894-900.

130 Leung JM, Davenport M, Wolff MJ, et al: IL22-producing CD4+ cells are depleted in actively inflamed colitis tissue. Mucosal Immunol 2014;7:124-133.

131 Gerlach K, Hwang Y, Nikolaev A, et al: TH9 cells that express the transcription factor PU.1 drive T cell-mediated colitis via IL-9 receptor signaling in intestinal epithelial cells. Nat Immunol 2014;15:676-686.

132 Nalleweg N, Chiriac MT, Podstawa E, et al: IL-9 and its receptor are predominantly involved in the pathogenesis of UC. Gut 2015; 64:743-755.

133 Granlund A, Flatberg A, Ostvik AE, et al: Whole genome gene expression meta-analysis of inflammatory bowel disease colon mucosa demonstrates lack of major differences between Crohn's disease and ulcerative colitis. PLoS One 2013;8:e56818.

134 Jiang W, Su J, Zhang X, et al: Elevated levels of Th17 cells and Th17-related cytokines are associated with disease activity in patients with inflammatory bowel disease. Inflamm Res 2014;63:943-950.

135 Kobayashi T, Okamoto S, Hisamatsu T, et al: IL23 differentially regulates the Th1/Th17 balance in ulcerative colitis and Crohn's disease. Gut 2008;57:1682-1689.
136 Liu Z, Yadav PK, Xu X, et al: The increased expression of IL-23 in inflammatory bowel disease promotes intraepithelial and lamina propria lymphocyte inflammatory responses and cytotoxicity. J Leukoc Biol 2011;89: 597-606.

137 Yu QT, Saruta M, Avanesyan A, et al: Expression and functional characterization of FOXP3+ CD4+ regulatory $\mathrm{T}$ cells in ulcerative colitis. Inflamm Bowel Dis 2007;13: 191-199.

138 Ueno A, Jijon H, Chan R, et al: Increased prevalence of circulating novel IL-17 secreting Foxp3 expressing CD4+ T cells and defective suppressive function of circulating Foxp3+ regulatory cells support plasticity between Th17 and regulatory T cells in inflammatory bowel disease patients. Inflamm Bowel Dis 2013;19:2522-2534.

139 Kumawat AK, Elgbratt K, Tysk C, et al: Reduced $\mathrm{T}$ cell receptor excision circle levels in the colonic mucosa of microscopic colitis patients indicate local proliferation rather than homing of peripheral lymphocytes to the inflamed mucosa. Biomed Res Int 2013; 2013:408638.

140 Shaz BH, Reddy SI, Ayata G, et al: Sequential clinical and histopathological changes in collagenous and lymphocytic colitis over time. Mod Pathol 2004;17:395-401.

141 Abdo AA, Urbanski SJ, Beck PL: Lymphocytic and collagenous colitis: the emerging entity of microscopic colitis. An update on pathophysiology, diagnosis and management. Can J Gastroenterol 2003;17:425432.

142 Armes J, Gee DC, Macrae FA, et al: Collagenous colitis: jejunal and colorectal pathology. J Clin Pathol 1992;45:784-787.

143 Goranzon C, Kumawat AK, HultgrenHornqvist E, et al: Immunohistochemical characterization of lymphocytes in microscopic colitis. J Crohns Colitis 2013;7:e434e442.

144 Johrens K, Grunbaum M, Anagnostopoulos I: Differences in the T-bet and GATA-3 expression patterns between lymphocytic colitis and coeliac disease. Virchows Arch 2010; 457:451-456.

145 Mosnier JF, Larvol L, Barge J, et al: Lymphocytic and collagenous colitis: an immunohistochemical study. Am J Gastroenterol 1996; 91:709-713.

146 Ouyang W, Lohning M, Gao Z, et al: Stat6independent GATA-3 autoactivation directs IL-4-independent Th2 development and commitment. Immunity 2000;12:27-37.

147 Bai S, Siegal GP, Jhala NC: Foxp3 expression patterns in microscopic colitides: a clinicopathologic study of 69 patients. Am J Clin Pathol 2012;137:931-936.

148 Park EK, Park YS, Park DR, et al: Cytokine expression of microscopic colitis including interleukin-17. Gut Liver 2015;9:381-387.
T Cells in Chronic Intestinal Inflammation
Inflamm Intest Dis 2016;1:52-62 DOI: $10.1159 / 000445133$ 
149 Kumawat AK, Nyhlin N, Wickbom A, et al: An in vitro model to evaluate the impact of the soluble factors from the colonic mucosa of collagenous colitis patients on T cells: enhanced production of IL-17A and IL-10 from peripheral CD4(+) T cells. Mediators Inflamm 2014;2014:879843.

150 Hueber W, Sands BE, Lewitzky S, et al: Secukinumab, a human anti-IL-17A monoclonal antibody, for moderate to severe Crohn's disease: unexpected results of a randomised, double-blind placebo-controlled trial. Gut 2012;61:1693-1700.
151 Reinisch W, de Villiers W, Bene L, et al: Fontolizumab in moderate to severe Crohn's disease: a phase 2, randomized, doubleblind, placebo-controlled, multiple-dose study. Inflamm Bowel Dis 2010;16:233-242.

152 Toedter G, Li K, Marano C, et al: Gene expression profiling and response signatures associated with differential responses to infliximab treatment in ulcerative colitis. Am J Gastroenterol 2011;106:1272-1280.

153 Caprioli F, Bose F, Rossi RL, et al: Reduction of CD68+ macrophages and decreased IL-17 expression in intestinal mucosa of patients with inflammatory bowel disease strongly correlate with endoscopic response and mucosal healing following infliximab therapy. Inflamm Bowel Dis 2013;19:729-739.
154 Rismo R, Olsen T, Cui G, et al: Mucosal cytokine gene expression profiles as biomarkers of response to infliximab in ulcerative colitis. Scand J Gastroenterol 2012;47:538547.

155 Costantino G, della Torre A, Lo Presti MA, et al: Treatment of life-threatening type I refractory coeliac disease with long-term infliximab. Dig Liver Dis 2008;40:74-77.

156 Gillett HR, Arnott ID, McIntyre M, et al: Successful infliximab treatment for steroidrefractory celiac disease: a case report. Gastroenterology 2002;122:800-805.

157 Chande N: Microscopic colitis: an approach to treatment. Can J Gastroenterol 2008;22: 686-688. 